\title{
POR UMA ABORDAGEM UNIVERSALISTA EM FILOSOFIA DA RELIGIÃO
}

FOR A UNIVERSALIST APPROACH IN PHILOSOPHY OF RELIGION

Adilson Koslowski*

\section{RESUMO}

A filosofia da religião tradicional tem sido marcada pelo estudo das crenças do teísmo (judaísmo, cristianismo e o islã), mas de modo mais restritivo tem-se focado nas crenças cristãs. Criticando essa abordagem, vamos contrapô-la a uma perspectiva universalista como sustentada pelo filósofo neozelandês Gregory W. Dawes fundamentalmente em seu livro Religion, Philosophy and Knowledge (2017). Nosso objetivo é apresentar esse programa de pesquisa filosófico como uma opção ao tradicional. A estratégia de Dawes é não focar no estudo das crenças, mas nas fontes do conhecimento religioso que ao mesmo tempo não são tantas, porém abarcam todas as religiões. Concluímos que essa nova abordagem tem várias vantagens em relação à anterior, pois vivemos em um mundo globalizado onde reina o pluralismo religioso.

PALAVRAS-CHAVE: Filosofia da religião. Gregory W. Dawes. Perspectiva universalista. Metafilosofia da religião.

\section{ABSTRACT}

The philosophy of traditional religion has been marked by the study of the beliefs of theism (Judaism, Christianity and Islam), but more restrictively has focused on Christian beliefs. Criticizing this approach, we will counter it to a universalist perspective as espoused by the New Zealander philosopher Gregory W. Dawes fundamentally in his book Religion, Philosophy and Knowledge (2017). Our goal is to present this philosophical research program as an option to the traditional one. Dawes's strategy is not to focus on the study of beliefs, but on the sources of religious knowledge that at the same time are not so many, but embrace all religions. We conclude that this new approach has several advantages over the previous one, since we live in a globalized world where religious pluralism reigns.

KEYWORDS: Philosophy of religion. Gregory W. Dawes. Universalist perspective. Metaphilosophy of religion.

\section{INTRODUÇÃO}

Este texto tem como objetivo apresentar uma nova metafilosofia da religião, a saber, uma perspectiva universalista e não centrada na crença religiosa como é tradicional em filosofia da religião. A vida se tornou globalizada, por isso, as religiões estão presentes em todas as partes do mundo. Não estão restritas a certos espaços. Nas sociedades modernas, as religiões são toleradas. As pessoas têm a liberdade de pertencer a alguma delas ou a nenhuma;

\footnotetext{
* Doutor em filosofia. Professor de Filosofia na UFS/DFL. E-mail: adilsonkoslowski@yahoo.com.br.
} 
bem como trocar de religião quando quiser. Essa situação é recente na história da humanidade. ${ }^{1}$ A filosofia da religião tem sido marcada pelo estudo da crença e de modo majoritário pelas crenças teístas, mas com acento quase exclusivo no cristianismo.

Alguns filósofos têm questionado essa perspectiva etnocêntrica e centrada na crença nos estudos filosóficos em religião ${ }^{2}$. O foco de nosso interesse é a proposta defendida e desenvolvida nos escritos do filósofo neozelandês Gregory W. Dawes, principalmente em seu livro Religion, Philosophy and Knowledge (2017).

Dawes critica a perspectiva tradicional nestes termos: ignora toda a religião que não tem crença em Deus; focada quase sempre no conteúdo da crença religiosa tais como a crença na existência de Deus, na coerência das propriedades divinas, no problema do mal e na existência do inferno etc. Para isso, basta conferir os sumários dos livros-textos em filosofia da religião ${ }^{3}$. Grande parte da discussão é centrada nas provas a favor e contra e existência de Deus. Desse modo, politeísmos, animismos etc. são deixados de lado; nesse mundo globalizado, as religiões estão presentes em todos os lugares. A perspectiva tradicional torna a religião algo de menos interessante. Além do mais, a filosofia da religião tradicional aparece com fortes traços apologéticos.

A metodologia proposta por Dawes é inovadora. Primeiro, a centralidade não é a crença religiosa, mas as fontes da crença religiosa. Mesmo que as religiões sejam muitas e suas crenças variadíssimas, as fontes são poucas e comuns. Ele divide as fontes da crença e do conhecimento religioso em quatro: conhecimento por meio de sinais; por contato ou familiaridade; por meio do discurso racional (argumentos) e por meio do testemunho (autoridade).

Segundo, a análise filosófica como método é limitada. A filosofia da religião tem que estar fortemente associada às pesquisas das ciências empíricas como a psicologia, a história, a biologia, a antropologia etc. As conclusões a respeito da religião não podem ser dadas de um modo apriorístico, mas devem ser feitas após avaliação dos dados das ciências que estudam a religião. A abordagem é fundamentalmente a posteriori e baseada nas descobertas feitas pela ciência. A religião é concebida como um objeto científico, não como um fruto de uma

\footnotetext{
${ }^{1}$ Em alguns países mulçumanos, há penalidades para a apostasia, incluindo a pena de morte.

${ }^{2}$ Confira Kevini Schilbrack (2014); "Global philosophy of religion and its challenges" de Yujin Nagasawa in Drapper e Schellenberg (2017); Timothy David Knepper (2013).

${ }^{3}$ Há muitos textos, mas o leitor poderá conferir Swinburne (2015); Rowe (2011); Tilghman (1996). Foco nos textos produzidos na tradição analítica, para uma crítica dos textos produzidos na tradição continental, veja Knepper (2003).
} 
revelação divina. Assim, há uma unidade entre o objeto da filosofia da religião e da ciência da religião ${ }^{4}$.

\section{A DEFINIÇÃO DE RELIGIÃo}

Dawes e Malclaurin (2013) enfrentam o problema da definição de religião. É um tema clássico, muitas propostas foram feitas. Dawes não está satisfeito com as definições que estão disponíveis na literatura. Eles oferecem uma definição baseada na literatura científica sobre religião feita por psicólogos cognitivistas e abordagens evolucionistas da religião. Evitam uma resposta puramente analítica ao problema.

Dawes e Malclaurin (2013) estão conscientes de que é difícil estabelecer uma definição de religião. Eles oferecem seis razões da dificuldade de definir religião: a natureza complexa das tradições religiosas; o chamado "problema do budismo"5; a problemática do próprio conceito de 'religião' ${ }^{\text {; }}$ a religião como um fenômeno complexo que não é esgotado nas crenças; as religiões não estão separadas entre si de modo claro, mas mantêm uma profunda ligação ${ }^{7}$. Por fim, definir uma religião parece implicar uma explicação da religião ${ }^{8}$.

Dawes e Malclaurin (2013) classificam as definições da religião em cinco tipos. i) As definições experimentais ou afetivas. Estas buscam estabelecer na relação pessoal do crente com a divindade o que vem a ser religião. Por exemplo, as definições de Rudolf Otto e Friedrich Schleiermacher. ii) As substantivas, que se centram nas crenças religiosas, como estabelecido pelo antropólogo E. B. Tylor, por Dan Sperber, Justin Barrett, Pascal Boyer e Scott Atran. iii) As funcionais, que se baseiam na função prática que tem a religião na vida das pessoas e na sua comunidade. Como é o caso do antropólogo Clifford Geertz ou do filósofo Keith Yandell. iv) As politéticas, baseando-se na técnica wittgensteiniana de semelhança de família, buscam um conjunto de caraterísticas comuns às religiões, mas não essenciais para o grupo ou classe. E, por fim, v) o agnosticismo definicional, que sustenta ser perda de tempo buscar uma definição apriorística de religião, dado o fraco resultado das tentativas já feitas. É possível que no fím da investigação cheguemos a uma teoria da religião.

\footnotetext{
${ }^{4}$ Nosso objetivo neste texto não é apresentar críticas à proposta de Dawes, mas sumarizá-la, tornando assim conhecidas novas formas de fazer filosofia da religião. Trata-se, portanto, de um texto introdutório ao assunto.

${ }^{5}$ Semelhante aos contraexemplos tipo Gettier em Epistemologia, o budismo primitivo (Theravada) não é uma religião centrada em Deus ou deuses, mesmo que eles existam não são centrais.

${ }^{6}$ Por exemplo, o hinduísmo é uma religião na acepção ocidental do termo? Marxismo e freudismo são religiões?

${ }^{7}$ Por exemplo, o judaísmo, cristianismo e islamismo.

${ }^{8}$ As conhecidas definições de Durkheim, Freud e do antropólogo Geertz pressupõem uma explicação.
} 
Dawes e Malclaurin (2013) não estão satisfeitos com a abordagem tradicional de definir religião por meio da análise que busca o que nós e nossa cultura estabelecemos como sendo uma religião. Definem a religião por um conjunto reduzido de processos naturais interrelacionados que une a diversidade das crenças e das práticas. A proposta é estabelecer o conceito de religião por meio da pesquisa empírica realizada na teoria evolutiva da religião e nas ciências cognitivas. A religião é explicada como um produto da evolução e da cognição. Assim, como a ciência estabeleceu o significado científico de espécies naturais como 'água', 'basalto', 'sistema solar' etc., de modo semelhante devemos estabelecer o conceito científico de religião, não apenas apoiado no senso comum, mas indo além dele 9 .

No caso das teorias evolutivas, há analogias entre a evolução das espécies e a evolução das religiões. Por exemplo, buscando uma taxionomia das religiões podemos estabelecer a evolução de uma religião a partir de outra. Mesmo que haja desanalogias entre a evolução das religiões e a evolução das espécies, é uma estratégia interessante para unificar as religiões e buscar suas origens. No caso das ciências cognitivas, busca estabelecer como as crenças são transmitidas, como são úteis para os indivíduos e para os grupos.

Se a religião for um produto da evolução, de adaptações, isso explica o fracasso das definições essencialistas. Em biologia o projeto essencialista fracassou tanto em basear-se apenas em aspectos genéticos ou morfológicos, pois leva em conta as propriedades históricas como um meio de definir a espécie e os grupos taxonômicos mais altos.

Dawes e Malclaurin (2013) sustentam a possibilidade de uma taxonomia cladística da religião, salvo as diferenças. Por exemplo, todas as espécies formam uma única árvore da vida, mas a religião não. Há muitas famílias de religiões.

As ciências cognitivas também podem ajudar nessa empreitada. Há cientistas cognitivos que estudam a relação entre análise cognitiva e evolucionária da religião. A religião depende que os crentes mantenham as crenças e as transmitam de forma bemsucedida. Por exemplo, cientistas cognitivos têm sustentado que é mais fácil lembrar-se de fatos que rompam as crenças ordinárias. Esse aspecto, por exemplo, ajuda a elucidar a grande variedade de crenças nesses processos criativos da religião, eliminando o banal em favor do extraordinário. Desse modo, unindo a teoria da evolução e as ciências cognitivas, torna-se possível buscar uma definição que unifique o objeto de estudo em ciência da religião e da filosofia. Essa é a proposta de Dawes para uma definição científica da religião.

\footnotetext{
${ }^{9}$ A filosofia analítica da religião - baseada na filosofia da linguagem comum - busca esclarecer a religião pela análise do significado da palavra 'religião' como é usado pela comunidade dos falantes.
} 
Dawes aceita que definir uma religião cientificamente é oferecer igualmente uma explicação do que seja religião. Desse modo, a definição de religião está atrelada ao programa de pesquisa em questão.

Em suma, se nossa interpretação estiver correta, a religião é um conjunto de práticas sociais que evoluem em face de pressões seletivas. Os vários problemas evolucionários pressionam o desenvolvimento de mecanismos cognitivos para o sucesso da religião.

\section{PENSAMENTO RELIGIOSO: O MITO E O RITO}

As religiões são fenômenos complexos. Segundo Ninian Smart $(1984,1989)$ as religiões têm sete dimensões. São elas: a dimensão do ritual, da doutrina, do mítico, do experiencial, do ético, do organizacional e do material. Frequentemente, quando alguém começa a participar de uma religião, a dimensão primeira é a do ritual, não é a da crença. Porém, há um vínculo profundo entre o ritual e a crença. A crença está incorporada no ritual. Este aspecto da religião é importante para Dawes, pois a religião não é apenas um conjunto de proposições, também um conjunto de comportamentos inteligentes que não envolvem pensamento reflexivo. Esse conhecimento é o que Gilbert Ryle chamou de conhecimento por habilidade (know-how).

Outro aspecto que Dawes (2017) sustenta ser importante na relação entre ritual e crença é de que o ritual incorpora crenças, bem como ajuda o crente a aceitá-las. Por exemplo, o ato de ajoelhar-se, de inclinar-se é um ato ritual de submissão. O participante de um rito é induzido a acreditar no que o rito pressupõe implicitamente, tacitamente. E além, certas partes do rito fazem com que a pessoa adquira conhecimentos que não possam, talvez, ser expressos por meio de palavras. A religião está permeada de práticas, de exercícios (ascese) que carregam em si conhecimentos não proposicionais.

Todavia, o rito necessita também de uma narrativa. Ele está vinculado a uma forma, a um modo de pensar, segundo Dawes (2017). Quem primeiramente propôs modos diversos de pensar foi o filósofo e sociólogo francês Lévy-Bruhl (1857-1939). Contudo, Dawes não sustenta que há qualquer sentido de progresso ou de descarte entre as formas de pensar como defendeu Comte. Todas elas estão ainda presentes na cultura atual. Dawes toma a teoria sobre os modos de pensar do psicólogo, neuroantropólogo e neurocientista cognitivo, o canadense Merlin Donald em Origens da mente humana (1991). 
Para Merlin Donald há três tipos de cultura. Essas culturas têm um modo próprio de pensar. Ele distingue três modos: o mimético, o mítico e o teórico. O pensamento mimético é baseado na imitação como no uso de expressões faciais, nos sons, nos gestos. Está presente desde o homo erectus há 1,5 milhões de anos, mesmo presente anteriormente entre alguns animais e pássaros; é facilmente percebido na cultura do homo sapiens de modo bastante intenso nos jogos infantis, na ópera e no cinema. Existe muito de mimese nos rituais religiosos. Os rituais são frequentemente recordações de eventos sagrados ancestrais.

A cultura mítica é baseada nas narrativas religiosas, nas cosmogonias, nas teogonias etc. São fontes para o rito. Além disso, o mito é formado por um conjunto de símbolos, metáforas. É normativo, apresenta-se como uma autoridade na explicação dos eventos que ocorrem no mundo e até da origem do próprio mundo. Ademais, os mitos oferecem arquétipos de como deveríamos ser, de como deveríamos nos comportar. O mito impera. De fato, há poucas divergências nas culturas ágrafas, dos nômades e das tribos em relação à autoridade do mito. Quanto mais a cultura é complexa e plural, a autoridade religiosa do mito e dos líderes religiosos tende a ser mais questionada e até abandonada, como no fenômeno do ateísmo.

Por fim, a cultura teórica é a que emerge da centralidade dada à experiência e ao argumento. A base da explicação é da experiência controlada pela razão. Também há uma separação entre o factual e o normativo. No Ocidente, a cultura teórica teve sua origem na Antiga Grécia do século VI a.C. por meio do pensamento filosófico-científico e sustentada em nossos dias numa cultura tecnocientífica.

A religião se expressa primevamente no mito. A expressão religiosa é mítica e incorporada no ritual. Outro aspecto importante do mito é sua função de provocar certas emoções e ações no ouvinte. Ele não fornece argumentos explícitos com o objetivo de esclarecer, defender ou facilitar a conversão religiosa por meio de razões. Porém, essa debilidade do mito será suprimida nas culturas teóricas. No teísmo (judaísmo, cristianismo e islã) o mito é traduzido em uma linguagem filosófica mais precisa, a saber, a teologia. Desse ponto de vista, a teologia é o esforço de tradução de um modo de pensamento para outro. Nas religiões orientais (por exemplo, hinduísmo, budismo), a dharmatologia, conforme a expressão de Dawes, também efetuará essa tradução. Expressões metafóricas como, por exemplo, "Jesus é o Filho de Deus" será traduzida em "Jesus é consubstancial ao Pai" (homoousios tou patrou). A teologia é a utilização da filosofia nas culturas teóricas como princípio hermenêutico dos mitos religiosos, como compreensão, defesa, coerência e razoabilidade. 
Para Dawes (2017), a cultura teórica e seu modo de pensar têm como objetivo predizer e controlar o curso dos eventos. Oferecer-nos a estrutura causal do mundo. Objetivos bem diferentes tem a cultura mítica, religiosa. O objetivo é duplo. Ela deseja garantir uma ordem sagrada. Essa ordem é expressão da vontade divina ou das leis do mundo sobrenatural. Ela é coletiva, vale para todos, para o grupo. Essa ordem está expressa no mito. Além de sustentar uma ordem social, a religião também oferece a salvação ou a libertação do coletivo e do indivíduo para este mundo e o vindouro.

\section{OS MODOS DE CONHECER DAS RELIGIÕES: SUAS FONTES EPISTÊMICAS}

O objetivo de Dawes (2017) é fornecer uma avaliação epistemológica da religião. As crenças religiosas são muitíssimo variadas, mas não as fontes do conhecimento religioso. Assim, podemos abordar a religião de um modo universal. Dawes identificou quatro dessas fontes: o conhecimento por meio de signos, pela familiaridade, por meio da razão discursiva (argumentos) e pelo testemunho (autoridade). Claramente essa divisão é uma abstração, pois, na realidade, essas fontes estão combinadas. Vejamos cada uma delas.

O conhecimento por meio de signos. ${ }^{10}$ Dawes está se referindo a três tipos: a adivinhação, os sonhos e as visões. A adivinhação "envolve a interpretação de objetos e eventos como um modo de adquirir conhecimento do futuro e da vontade dos deuses" (DAWES, 2017, p. 55). Ele não deseja julgar aprioristicamente essa fonte como não confiável e apenas fruto da esperteza e da ignorância dos povos. Toma a sério as reflexões do filósofo e estadista romano Cícero (apud DAWES, 2017, p. 56, tradução nossa):

Eu vejo que não existe nenhum povo muito civilizado ou educado ou muito selvagem e muito bárbaro que não sustenta que sinais do futuro podem ser dados e podem ser entendidos e anunciados antecipadamente por certos indivíduos.

Por que há tantas técnicas adivinhatórias nas culturas? Segundo Dawes (2017) um dos motivos é a relutância de acreditar no acaso. É uma busca por uma explicação. Os eventos são produzidos pelo mundo sobrenatural, são intencionais. O que chama atenção é que os acertos nas adivinhações são maiores do que os erros ou a pura arbitrariedade. E parece ter a

\footnotetext{
${ }^{10}$ Dawes faz essa divisão tripartite dos signos utilizando a terminologia de Peirce para os signos linguísticos. Confira Dawes (2017, p. 53).
} 
adivinhação uma capacidade de resolver certos problemas que não poderiam ser resolvidos por outras vias.

Uma justificação que Dawes não levanta em seus estudos é oferecida pelo professor de história da Grécia Antiga Donald Kagan. Ele sustenta que os oráculos de Delfos ofereciam informações bastante confiáveis, pois os sacerdotes da época eram muito bem informados. Muitas pessoas e de diferentes lugares iam ao templo, mantinham os sacerdotes bem informados. A fonte era razoavelmente confiável e as informações valiosas. Dawes oferece uma explicação da justificação dessa fonte de um modo diferente como veremos abaixo.

Os sonhos e as visões são meios muito usados como fontes de conhecimento religioso $^{11}$. Dawes (2017) baseando-se no especialista das sociedades antigas do Oriente Médio, como Michele Stephen, sustenta três tipos de sonhos. Os sonhos podem ser revelações de uma divindade, refletir a saúde do corpo e do espírito, ser profecias de eventos futuros.

Como avaliar epistemicamente essas fontes de conhecimento que são a adivinhação, os sonhos e as visões? Para Dawes não são elas fruto apenas de arbitrariedade e de enganação. Um modo naturalista de explicá-las é seguindo o modelo do processo dual da psicologia experimental que distingue entre o nível consciente e o não consciente, a saber, a cognição inconsciente. Nem todo processo cognitivo é elaborado conscientemente, e podemos saber algumas coisas apenas por meio desse tipo de processo. Ocasionalmente podem nos fornecer crenças produzidas de um modo confiável. Porém, Dawes sustenta que uma explicação baseada no mundo sobrenatural seria igualmente uma hipótese a priori cientificamente plausível $^{12}$. Ele não acha que possamos resolver essas questões simplesmente apelando para algum critério apriorístico ou o naturalismo metodológico. Não há nada na história da ciência que desabone a possibilidade de uma entidade sobrenatural ser a explicação de algo. Todavia, argumenta que a ciência moderna rejeitou - até o presente momento - as hipóteses científicas teístas, pois são epistemicamente inferiores às naturais.

Outra fonte do conhecimento religioso é a experiência mística. A experiência mística é um tipo de conhecimento direto, não inferencial. Mesmo que alguns pensadores religiosos ${ }^{13}$ têm sido críticos da experiência mística, ela faz parte das religiões e não é possível desprezála globalmente e manter a coerência. Ela é frequentemente vista como uma forma superior ao

\footnotetext{
${ }^{11}$ Antigo Testamento Joel 2-28; Novo Testamento Mateus 1, 20-21; 2:13; 2, 19-20; 2:21; Corão 8:43 (Os espólios). A adivinhação tem sido criticada entre as religiões, principalmente entre os teístas. Todavia, os sonhos são muito importantes como uma fonte de revelação.

${ }^{12}$ Para maiores detalhes dessa tese de Dawes sobre a legitimidade da explicação científica teísta confira Dawes $(2009,2011)$.

${ }^{13}$ Dawes se refere ao famoso teólogo protestante Karl Barth.
} 
conhecimento proposicional e inferencial, pois é entendida como uma forma de conhecimento (intuição) que ultrapassa os limites da experiência sensível e dos conceitos. Quase sempre é regulada com regras rígidas por parte das comunidades religiosas, principalmente se vierem a ferir a revelação pública como contida nos livros sagrados da Bíblia, do Novo Testamento, do Corão, dos Vedas etc.

Outro aspecto notado por Dawes (2017) é de que a experiência mística é bastante diversa entre as diferentes tradições religiosas. Tais como a experiência do Deus cristão, da unidade do Brahman e do Atman, da experiência zen budista etc. Os estudiosos têm divergido muito a respeito de como entender esse fenômeno. Existe a tese da diversidade intrínseca que sustenta que cada tradição religiosa tem sua própria experiência mística, pois não há experiência que não seja sintetizada com os conceitos próprios daquela tradição. A experiência mística é intrinsicamente uma construção cultural. Por outro lado, há os que sustentam a tese do núcleo comum. Para além das representações culturais típicas de cada tradição cultural há um núcleo de experiências comuns que transcendem as peculiaridades das religiões particulares.

Em relação à confiabilidade epistêmica dessa fonte de conhecimento religioso, depois de mostrar várias formas de explicação filosóficas, naturais e teológicas, Dawes rejeita a argumentação da analogia da experiência mística com a experiência sensorial comum como sustentada pelo filósofo William Alston (1991). Parece-lhe ser o argumento mais forte em prol da confiabilidade epistêmica, pois se baseia nas semelhanças com a experiência sensorial. Desse modo, a experiência mística teria uma justificação prima facie. Alega, porém, que diferentemente da experiência sensorial que tem sua fonte nos sentidos, não temos ideia qual seja a fonte da experiência mística. Há desanalogias suficientemente fortes, segundo Dawes, para não aceitarmos o argumento de Alston.

Um modo tradicional de defender o caráter cognitivo da experiência mística é sustentar que ela seja autoautenticada. A saber, a experiência em si garante sua veracidade, pois transcende o proposicional, o conceitual que lhe é inferior. Porém, essa defesa é falha para Dawes, pois as tradições religiosas não aceitam as experiências místicas como autoautenticadas. Não sabemos qual é a fonte dessas experiências. Também não temos evidências para saber se a fonte da experiência mística é confiável enquanto processo. E qualquer tentativa de verificar o conteúdo das experiências larga mão da autoautenticação, pois estaremos buscando evidências para sustentá-la. 
Uma defesa é de que a experiência mística é autoautenticada para o indivíduo que as tem. A experiência fornece evidência privada ao místico. A evidência fornecida pela experiência mística tem um caráter impositivo. O místico tem dificuldades de negá-la. Não há um controle doxástico sobre a experiência e seu conteúdo.

Dawes sustenta que são possíveis também testes não religiosos ${ }^{14}$, entre eles: confrontar as alegações a que o místico diz ter acesso e as possíveis consequências empíricas daquelas alegações; verificar a consistência das alegações místicas com outras crenças bem estabelecidas. Para Dawes, a experiência mística necessita ser avaliada, ela não é autoautenticada.

Outra fonte é a razão, o discurso da razão. O evidencialismo é uma tese epistemológica que sustenta que devemos aceitar uma crença se temos razões para isso; no caso da religião, se há argumentos que nos forneçam provas, razões para crermos. Há os clássicos argumentos a priori, como o argumento ontológico desde a versão original de Anselmo, como a de Descartes, Hegel, Malcolm, Plantinga, etc.; bem como os argumentos a posteriori, como as várias versões dos argumentos cosmológicos e os teleológicos. Depois de analisá-los, mostrar limites e dificuldades, Dawes não acha impossível receber objeções a suas críticas aos argumentos por parte de filósofos teístas. Acha mesmo que seja possível provar a existência de Deus, mas considera o conteúdo das provas muito restrito (teísmo restrito) comparado às crenças que as religiões têm a respeito de Deus (teísmo ampliado).

Mas há algo sui generis na religião em relação aos argumentos que providenciam algum tipo de prova para as crenças religiosas, seja para a existência de Deus ou mesmo para alguma doutrina religiosa, por exemplo, a ressureição de Jesus. Primeiramente, a crença religiosa não é o tipo de crença que se satisfaz com qualquer grau de certeza, mas o grau máximo. Entre o 0 e 1 do cálculo de probabilidade, o grau é 1. Essa exigência é tão elevada que não há como as melhores provas garantirem tal certeza. Por isso, para Dawes os argumentos não podem fornecer a base para a crença religiosa (teísmo ampliado). Segundo, as religiões não estão baseadas na razão, a crença religiosa tem sua base na fé. Por melhores que sejam os argumentos eles podem ser apenas preâmbulos da fé (preambula fidei) como em Tomás de Aquino ou "pressuposições da fé”, em Calvino. O que a razão pode fornecer é apenas um justificação incompleta da religião. A razão tem uma finalidade meramente

\footnotetext{
${ }^{14}$ Há testes religiosos, por exemplo, a coerência com a doutrina ortodoxa da religião em questão. No caso do catolicismo, há, por exemplo, o discernimento dos espíritos em caso de alguma experiência religiosa ser de Deus ou do demônio. No caso do demônio, a pessoa ter força mais do que o normal, falar línguas antigas e saber segredos do coração são critérios - não suficientes - mas indicam possessão diabólica (TANQUEREY, 2017).
} 
instrumental ou, como diziam os filósofos medievais: "a filosofia é a serva da teologia" (philosophia ancilla theologiae). Os argumentos, as evidências são secundárias nas religiões. Votaremos abaixo a essa questão.

Por fim, a última fonte de conhecimento é o testemunho, a autoridade. O testemunho como uma fonte de conhecimento é algo majoritariamente admitido na epistemologia contemporânea, porém há divergências de como conceber sua justificação. É certamente um conhecimento de segunda mão, baseado na autoridade, na confiabilidade da fonte. Nas religiões, o testemunho é fundamental. A religião transmite esse testemunho para outros membros que estão frequentemente muito distante dos eventos históricos que são sua fonte.

Nas religiões, os processos de possessão, $\operatorname{profecia}^{15}$ são muito importantes. Há intermediários entre os homens, Deus, os deuses e o mundo sobrenatural. Dawes se dedica em analisar epistemicamente a profecia. Não descarta explicações antropológicas e psicológicas como a de obter status social, controle, chamar atenção etc., mas não despreza o caráter ocasionalmente confiável de processos cognitivos inconscientes como já acima exposto.

A própria Bíblia (Dt 18: 21-22; 13, 1-13; 1 Jo 4: 1-3) fornece critérios para verificar se as alegações proféticas são verdadeiras: a) verificar se as profecias se cumprem; b) verificar se as profecias não ferem algum princípio da religião. O primeiro não é um princípio muito útil. Porém, mesmo que se realiza, não é por si só garantido, pois não é autoautenticado. Todavia, as religiões tendem a diminuir o máximo possível o papel do intermediário e focar na fonte dessas revelações, que é a própria divindade.

A revelação é a palavra do próprio Deus ou deuses ou do sábio pontificada pelo possuído, profeta, visionário, místico, discípulo e, às vezes, até pelo próprio Deus como no caso de Khrisna (avatar de Vishnu) ou em Jesus de Nazaré (segunda pessoa da Trindade, o Verbo). Dawes sustenta que a ideia de revelação é bastante comum e está presente em todas as religiões. Mesmo as religiões ágrafas possuem essa ideia. Os aborígenes da Austrália sustentam que certos desenhos rupestres foram produzidos pelos deuses.

A ideia de revelação não está presente explicitamente nas culturas ágrafas e tribais como é o caso do judaísmo, cristianismo e islã. Todavia, segundo Dawes, há revelações também fora das religiões teístas como no hinduísmo ou no budismo.

\footnotetext{
${ }^{15}$ Para Dawes existe um vínculo estreito entre a possessão e a profecia judaica. Confira Num 24:4; 1Sam 10:5; 1Sam 19: 23-24; Reis 3, 15-16. Segundo Dawes - ele mesmo um exegeta profissional -, a possessão (profecia) encontra-se nas fontes mais antigas da escritura judaica e será posteriormente substituída pela visão dada uma nova concepção de Deus.
} 
Os hindus separam suas escrituras em shruti (aquele que é ouvido) e smrti (aquele que é lembrado). Os textos revelados são os shruti que são os Vedas. São os "não vindos do homem" (apauruseya) ${ }^{16}$. Enquanto no caso do budismo, que parece o mais improvável, são considerados os ensinamentos e as práticas ensinadas por Buda como uma revelação. Dawes entende desse modo, pois esses ensinamentos e práticas devem ser aceitos pela fé (saddha).

\section{A fé como resposta à revelação}

Para Dawes, a atitude do crente perante a revelação é aceitá-la na fé. A fé tem um lugar fundamental na religião. Mesmo que esta alegação seja considerada algo trivial, não deixa de ser muito importante. Mas os filósofos têm desafiado essa orientação central das religiões. Para Dawes, um clássico exemplo disso foi o empirista inglês John Locke no seu livro IV contido em sua famosa obra Ensaio sobre o entendimento humano (1690).

Segundo Locke, decidir-se por uma religião é uma decisão que deve ser tomada pela razão. O juiz é sempre a razão. Ela é o tribunal e a instância última de nossas decisões epistêmicas. A razão deve nos fornecer as razões para aceitar que há uma revelação. Se Deus falou por meio dessa revelação e sendo onisciente, onipotente, onipresente e bom, tudo o que revela é digno de confiança no maior dos níveis de certeza. Para Locke é possível provar a existência de Deus e justificar a revelação cristã. Locke é um evidencialista.

Divergindo fortemente dessa posição filosófica, os teólogos sustentam que a fé é a resposta à revelação, e não a razão. Dawes pensa que a posição de Aquino e Calvino é representativa e pode ser generalizada para todas as religiões ${ }^{17}$. Não é a razão que é a fonte da confiabilidade e certeza via evidências. A racionalidade do ato da fé é de que a fé é autoautenticada. Acredita-se na revelação porque foi Deus que a revelou. E Ele não engana e nem se engana.

Para Dawes, há um sério problema nessa argumentação teológica. Se acreditarmos nessa doutrina pela autoridade divina, como sabemos que essa suposta revelação é de fato revelada por Deus? A resposta é novamente de ser pela autoridade divina. Há uma clara circularidade nesse modo de argumentar. Uma das possibilidades de resposta é sustentar que o ato da fé não é proposicional, mas um ato amoroso de confiança em Deus em reposta a um

\footnotetext{
${ }^{16}$ Para maiores detalhes confira Siri A. A. K Ayer.

${ }^{17}$ Para maiores detalhes confira Dawes (2015).
} 
dom. Mesmo assim, estamos apenas assumindo que o processo é confiável (externalismo epistemológico), mas isso tem que ser demonstrado para Dawes.

Na perspectiva de Dawes, depois de analisar as fontes de conhecimento religioso, não há nenhuma que pode garantir a justificação ou a confiabilidade como uma fonte segura para obter conhecimento na maior parte das vezes. Mesmo os argumentos advindos da fonte da razão considerando-os cogentes, não podem garantir certeza absoluta que a religião exige. Por fim, a fé baseada na autoridade autoautenticada também se apresenta problemática por ser circular.

Para Dawes uma possibilidade de manter a crença religiosa que é muito importante para a vida de muitas pessoas neste planeta é a de sustentar uma perspectiva pragmática semelhante à aposta de Pascal, porém adaptada de um modo mais rigoroso por Richard Swinburne (1981).

Para concluir, Dawes pensa que a expressão "crença religiosa" não parece adequada, mesmo que continuemos a usá-la por comodidade. Sustenta, como fazem muitos epistemólogos atuais, que a crença é algo que se impõe ao sujeito. Ela é incontrolável e não depende da vontade do agente epistêmico (involuntarismo doxástico). Assim, acreditar que "Agora é noite" sendo que se sabe que agora é dia não está obviamente sob o controle doxástico. A palavra mais adequada seria o de "aceitar". As pessoas aceitam determinada religião, revelação, determinadas "verdades de fé". Sua posição é claramente desfavorável ao voluntarismo doxástico. Deste modo, " $S$ crê que Jesus ressuscitou" ou "S crê que Deus é trino", seriam melhores traduzidas como: " $S$ aceita que Jesus ressuscitou" e "S aceita que Deus é trino".

\section{CONCLUSÃO}

Nossa pretensão neste texto foi sumarizar a posição e a metodologia inovadora de Dawes a respeito de como fazer uma filosofia da religião universal e não apologética, empírica, sensível à ciência da religião, não apriorística. Uma filosofia não centrada no conceito de crença religiosa e reduzida aos teísmos.

Os dois aspectos principais, segundo nossa intepretação, é centrar os estudos filosóficos nas fontes da religião que são apenas quatro e, ainda, não utilizar apenas o método analítico para resolver as questões, mas sim centrar-se nos resultados estabelecidos empiricamente pelas ciências que estudam as religiões. 
Pensamos que esse tipo de metafilosofia da religião traz uma nova forma de fazer filosofia da religião, e intimamente conectada com a ciência da religião, tirando do isolamento os filósofos da religião centrados apenas na análise, ou reduzidos a comentários dos clássicos em filosofia da religião.

Dawes incentiva que a filosofia da religião tome como base as ciências empíricas no sentido da psicologia empírica, antropologia cultural, história, biologia, etc.; não em teorias especulativas tais como as de Freud, de Jung, que por vezes são menos cautelosas.

De tudo o que foi dito até aqui sobre a metafilosofia da religião de Dawes podemos afirmar que é mais universal, não etnocêntrica ou apologética como é - às vezes - a filosofia tradicional da religião. A filosofia tradicional centrada na crença e nos teísmos não é desprezada, é assimilada, porém é uma faceta do grandioso e interessante mundo que são as religiões.

Além disso, uma filosofia da religião que seja importante para todos, não só no sentido de estender nossa compreensão das religiões, mas de auxiliar na tomada de decisões de uma forma racional.

\section{REFERÊNCIAS}

ALCORÃO. Disponível em: http://www.islambrasil.com/kuran_txt/index.htm. Acesso em: 03 mar. 2018.

ALSTON, William. Perceiving God: the epistemology of religious experience. Ithaca: Cornell University Press, 1991.

AYER, Vaikunta Anantha Krishnan. Hindu scriptures. Disponível em: http://www.hinduism.co.za/vedas-.htm. Acesso em: 02 mar. 2018.

BÍBLIA DE JERUSALÉM. São Paulo: Paulinas, 1985.

DAWES, W. Gregory. Theism and explanation. New York and London: Rutledge, 2009.

DAWES, W. Gregory. In defense of naturalism. Int. J. Philos Relig, 70, p. 3-25, 2011.

DAWES, W. Gregory. The act of faith: Aquinas and the moderns. In: KVANVIG, Jonathan.

Oxford Studies in Philosophy of Religion. London: Oxford University Press, 2015.

DAWES, W. Gregory. Religion, Philosophy and Knowledge. London: Palgrave Macmillan, 2017.

DAWES, W. Gregory; MACLAURIN, James. What is religion? A new science religion. London: Routledge, 2013. 
DONALD, Merlin. Origens do pensamento moderno. Lisboa: Fundação Calouste Gulbenkian, 1999.

DRAPER, P. ; SCHELLENBERG, J. L. Renewing philosophy of religion: exploratory Essays. New York: Oxford University Press, 2017.

KAGAN, Donald. Curso sobre a Grécia Antiga. Disponível em: https://www.youtube.com/watch?v=FQba5PCI3hg. Acesso em: 02 mar. 2018.

KNEPPER, Timothy D. The ends of philosophy of religion: terminus and telos. New York: Palgrave Macmillan, 2013.

LOCKE, John. Ensaio sobre o entendimento humano. Lisboa: Fundação Calouste Gulbenkian, 2014.

ROWE, William L. Introdução à filosofia da religião. Lisboa: Verbo, 2011.

SCHILBRACK, Kevin. Philosophy and the study of religion. Oxford: Routledge, 2014.

SMART, Ninian. The religious experience of mankind. New Jersey: Printice Hall, 1984.

SMART, Ninian. The word's religions: old traditions and modern transformations.

Cambridge: Cambridge University Press, 1989.

SWINBURNE, Richard. Faith and reason. Oxford: Clarendon Press, 1981.

SWINBURNE, Richard. A existência de Deus. Academia Monergista, 2015.

TANQUEREY, Adolphe. Compêndio de teologia ascética e mística. São Paulo: Cultor de Livros, 2017.

TILGHMAN, B. R. Introdução à filosofia da religião. São Paulo: Vozes, 1996. 